Article

\title{
Online Clothing Resale: A Practice Theory Approach to Evaluate Sustainable Consumption Gains
}

\author{
Cosette M. Joyner Armstrong *, Hyejune Park \\ Oklahoma State University, 34A Human Sciences, Stillwater, OK 74075, USA \\ * Correspondence: Cosette M. Joyner Armstrong, \\ Email: cosette.armstrong@okstate.edu; Tel.: +1-405-744-9525.
}

\begin{abstract}
Collaborative consumption businesses such as online clothing resale (OCR) platforms seem poised to increase the utilization of clothing, prevent premature disposal, and decrease dependence on new clothing production, which are important environmental gains. OCR also embodies features of social media, providing at least the appearance of a community that cares about waste reduction or recycling. However, these platforms conjure skepticism about the capacity to meaningfully foster sustainable consumption, as they are positioned similarly to the fast fashion marketplace. This study took a practice theory approach to investigate the actual behavior of OCR users; young women who have utilized a variety of OCR platforms to buy and sell clothing. The objective of the study was to understand the extent to which the practice of OCR aligns with fundamental arguments that implicate it as a model for sustainable consumption: reduced production, disposal mitigation, and changed behavior via sociality. Interviews were conducted with 24 female participants. Practice theory guided data analysis, which included data reduction by sorting user experiences into routines and then categorizing each routine by materials, competences, and meanings associated with the practice. Then, themes characterizing the practice were identified. Findings revealed that OCR practice only loosely supports sustainable consumption. A culture that values second-hand clothing exchange is absent from the practice, and the capacity of OCR to meaningfully support product longevity is undermined by a lack of second-hand circularity and a desire among practitioners to acquire like new or barely worn goods at a price they could not ordinarily afford.
\end{abstract}

\section{G Open Access}

Received: 04 February 2020

Accepted: 21 March 2020

Published: 26 March 2020

Copyright $(\odot 2020$ by the author(s). Licensee Hapres, London, United Kingdom. This is an open access article distributed under the terms and conditions of Creative Commons Attribution 4.0 International License.

KEYWORDS: clothing; resale; practice theory; collaborative consumption

\section{INTRODUCTION}

Online collaborative consumption has opened new possibilities for sustainable consumption. To be sure, any value proposition that increases the utilization of a product, prevents disposal, and decreases dependence on new production is an environmental gain [1,2]. However, 
current collaborative clothing consumption platforms conjure skepticism about the capacity to meaningfully advance consumer behavior toward sustainable ends, as platforms are seemingly positioned similarly to fast fashion [3]. Park and Joyner Armstrong [4] propose two primary categories of online collaborative consumption in the clothing industry; those that provide only utility, without ownership (e.g., renting) [5], and the redistribution of second-hand goods [1]. This study focuses on the latter: the procurement of still-valuable second-hand clothing and the redistribution of under-utilized garments to new owners via online clothing resale (OCR) platforms (While some OCR platforms may carry goods that are "like new" and still tagged, which might not have been worn, they are not the same as "new", since they have been owned previously. The term "second-hand" in this study follows its dictionary meaning: not new and has been owned by someone else).

Less than one percent of materials used to make clothing are recycled for new clothing, a $\$ 100$ billion annual loss [6]; the end-of-use phase being one of the weakest areas of the clothing value chain [7]. Certainly, sharing platforms partly emerged in response to such statistics [8], and OCR stands to address a 36\% drop in garment utilization in the last 15 years [6]. Though second-hand trade is not new, technological advancements have dramatically increased the exchange capacity of this industry sector [9], making the cost and ease of interaction between numerous buyers and sellers much easier [8-10]; many online platforms of which embody the features of social media. Compared to traditional methods of second-hand exchange, such as consignment and resale stores or swap meets, OCR platforms such as Poshmark, Mercari, and ThredUp represent a substantive marketplace for used clothing and provide opportunities for product life extension by increasing the utilization of clothing items [11]. Yet, questions exist about aspects of these platforms that could negate environmental advancements [5], such as packaging and transportation requirements [2], low levels of peer-peer interaction [12,13], and the positioning of platforms [14].

In their extensive literature review, Iran and Schrader (2017) [15] discussed that second-hand clothing consumption may positively contribute to the environment by intensifying product use and extending the product's life while also creating rebound effects due to extra consumption of many, inexpensive items. Yet, the contributions and drawbacks manifest in actual practice of OCR remains unclear. Several researchers have found that the consumer's environmental consciousness is an important influence over the decision to engage in collaborative consumption [8,12,16-19]; however, these approaches have been largely based on the theory of planned behavior, which assumes that behavior derives from attitudes and intentions. The chief downfall of such a tact is that attitudes or values that are determined to influence behavior in one context are often erroneously assumed to influence behavior in all other similar contexts, an implausible feat [20]. Røpke [21] 
urges the use of a practice lens to understand the practices that people carry out, not because of environmental intentions but due to everyday interests.

To address this important gap in the literature, a practice theory approach was adopted in this study to investigate actual behavior of OCR. Specifically, the objective of this study was to understand the extent to which the practice of OCR aligns with fundamental arguments that implicate it as a model for sustainable consumption: reduced production, disposal mitigation, and changed behavior via sociality. From a practice theory perspective, behavior is motivated by everyday concerns in life [21,22]. Often, engaging in a practice rather than a cognitive decision is what shapes behavior, not the other way around [20,23]. By examining how consumers engage in OCR, the ways in which the practice of OCR functionally delivers sustainability gains (or does not) was illuminated. Drawing from practice theory, the researchers examined key routines, the competences requisite for effective practice, and consumers' perceptions of OCR and their own consumption activity. Two research questions were developed to guide inquiry and analysis: (1) Does OCR reduce demand for new production and mitigate premature disposal? and (2) Does OCR foster sociality that facilitates shared values and identity around sustainable consumption behavior?

\section{BACKGROUND}

\section{Online Clothing Resale (OCR) as Practice}

In the context of OCR, clothing is redistributed via online consignment, auction, or swapping in which used goods are resold to become owned once again, and the access period is undefined [1]. Redistributed ownership will soon top $\$ 33$ billion in annual sales, a sector that is growing 20 times faster than traditional retail outlets and five times faster than off-price retailing [24]. Undoubtedly, the growth of OCR is a consequence of technological advances making it easier and less costly for an expansive network of users to connect, interact, and exchange goods [9,24], especially among younger consumers [24]. This highlights OCR as a practice involving tools, know-how, and techniques required to utilize these platforms.

A practice is an everyday routine, such as cooking or shopping [20]. Consumers, who are considered 'practitioners,' integrate materials, competence (knowledge/skills), and meanings in their performances or actions of the practice, creating linkages between them [21]. Practice theory moves beyond economic theories that are dependent on a rational actor as well as theories that seek social- or identity-related explanations for behavior by looking at the actual behaviors involved in a consumptive practice. This approach shifts the focus of concern from consumer to practitioner [25]. Researchers have argued that the practice approach is particularly relevant to environmentally related 
consumption since consumption activities are often shaped by routines and habits rather than a rational endeavor [21,26,27]. Røpke [21] argues that most consumers are unaware of the environmental impact of their consumption routines, as this impact is not a part of the meaning consumers associate with their consumption practice. For research inquiry, importance is placed on understanding the practicalities of consumption, offering more mechanisms for behavior change than simply altering attitudes or values. Barriers to behavior change become more apparent by examining how ordinary life is organized. By understanding real practice, changes in collective action can be identified [20].

\section{OCR and the Environmental Gains of Product Longevity}

For clothing, sustainable clothing consumption is chiefly promoted via product longevity [28], which is influenced by aspects of design and production [29,30] as well as consumer practice [31]. The utilization of second-hand goods reduces the demand for new products and mitigates premature disposal [2,15]. Iran and Schrader [15] argue that when OCR substitutes the acquisition of new products, consumption needs can be satisfied with less material throughput. Joyner Armstrong and Park [3] claim that since OCR allows people to 'own' a product, it fosters an individual's attachment to an item, thereby yielding product longevity, which may not hold true for some other types of collaborative consumption like short-term renting of clothing products. OCR also supports environmental sustainability by increasing material utilization. OCR platforms like Poshmark and Facebook Marketplace certainly contribute to the delayed disposal of clothing and the reduction of production demand by helping platform users sell their under-utilized clothing and buy second-hand goods [2,5]. This exchange is considered an important part of achieving clothing circularity in the consumer use phase [11]. Several life-cycle analysis papers have illustrated that substituting new clothes with second-hand clothing purchase can make a positive impact on the environment by saving energy and decreasing global warming and human toxicity of materials [32,33].

From a consumer's perspective, one might expect that these environmental gains, as perceived by consumers, positively influence their adoption and use of OCR. Yet, the empirical evidence to support this claim is, at best, mixed. Hamari et al. [8] examined the impact of a series of motivations on consumers' attitude and intention to engage in collaborative consumption, which is somewhat loosely defined to include different consumption modes like sharing, renting, swapping, and trading within a community. They found that perceived environmental sustainability predicted an attitude but not intentions toward collaborative consumption. Parguel et al. [19] approached OCR in a slightly different perspective in that they focused on indulgent consumption on OCR platforms and examined whether perceived 
environmental sustainability would encourage overconsumption of unnecessary products. Their findings indicate that environmentally conscious consumers engaged in more indulgent behaviors, as OCR platforms are viewed as an environmentally beneficial consumption mode. This result relates to some rebound effects of OCR discussed by other researchers, such as the possibility for OCR to make an abundance of cheap fashion even more available as well as to provide access to goods one cannot ordinarily afford, considered extra consumption [3,15]. More recently, Park and Joyner Armstrong [4] interviewed users of OCR and noted that perceived environmental sustainability as a motivation did not emerge in their data. If environmental sustainability has marginal or little impact on the actual behavior within OCR, how practitioners of OCR realistically utilize these platforms begs for illumination.

\section{OCR and Potential for Behavior Change via Sociality}

A potential powerful mechanism to shift behavior via a practice is reflected in at least the appearance of sociality via OCR's social media type features. It has been argued that when self-organization and peer-to-peer interaction facilitate the development of shared values and personal identity, consequently, changes may occur in consumption behavior [12,13,15]. Sociality is crucial for developing a sense of community around behavior, which can even lead to political consumerism, observed often in non-clothing related swapping and renting research [34-36]. Jaeger-Erben et al. [12] argue that the more self-organization is permitted within collaborative consumption by involved and engaged consumers, the more viable an alternative consumption practice can become. For instance, the sociality offered by clothing "swapping parties" might afford one to come in contact with others who are also concerned about fashion's darker side, which may lead to greater acceptance of second-hand goods and greater visibility of this consumption model [15]. In the context of OCR, most platforms such as Listia and Poshmark largely depend on the community of users since inventory is created with the users' own goods, and buying and selling used-goods via the platform require a certain level of cooperation. Perhaps, this is because OCR platforms embody relatively low levels of peer-to-peer interaction and few features to foster real community, driving skepticism about its potential to buoy sustainable consumption [3]. Nevertheless, research has implicated collaborative consumption in the development of social capital that empowers participants to more fundamentally modify their behavior to sustainable aims [12,37], and the ability to influence social change is often a featured driver in sustainable business model conceptualization [38]. It must also be noted that previous research has highlighted consumer concerns about the trustworthiness of these platforms, which may not poise this online environment for sociality [39-41]. Generally, the social aspects of 
sustainability within OCR have received a dearth of research attention compared to its environmental benefits [15]. It also arguably remains a question as to whether OCR is, in fact, an alternative consumption behavior.

\section{MATERIALS AND METHODS}

An interpretative approach was adopted in this study to empirically verify the theoretical underpinnings of OCR. Drawing from practice theory, the illustration of everyday life served as guide points for evaluation of the ways in which the practice of OCR aligns (or does not) with fundamental arguments that implicate OCR as a sustainable consumption activity. To do this, in-depth interviews with the users of OCR platforms were conducted. The researchers received approval from the university's Institutional Review Board for human subjects research prior to the commencement of the study.

\section{Data Collection}

Since current OCR platforms for clothing are predominantly used by female consumers [33], a mass email was sent to 5000 female faculty, staff, and students enrolled in or employed at three campuses that are part of a large Southwestern university in the U.S. Though sourcing participants through a university limits generalizability to some extent, for an exploratory study of this nature, it was appropriate. Those who were interested in participating in the study completed a brief screening survey to verify users of various collaborative platforms and collect basic demographic and other descriptive information. A USD 15 cash incentive was provided to participants. The interview questions consisted of two primary topics: what prompted their initial choice of OCR as well as how and why they have used the features of OCR platforms (e.g., website navigation, financial arrangement, interaction with other users). Phone interviews were conducted until a saturation in user experience was reached, which included 24 participants from age 18-40, with most participants in the 18-22 age range. Though most participants were young, OCR has received some of its highest engagement from younger consumers [24].

\section{Data Analysis}

Røpke [21] suggests a method for analyzing consumption studies in accordance with practice theory to initially include three broad interrelated categories: material, meaning, and competence. Røpke [21] argues that these aspects belong to the practice, not the individual, which is what characterizes a practice by a social group. Using Nvivo data analysis software, the data (e.g., interview transcripts) were first reduced by categorizing it into the basic performances or actions: the routines of the practice as described by participants [22]. Then, using constant 
comparative technique, aspects of these routines were coded across the three above-mentioned categories [42]. This analysis resulted in a detailed illustration of the practice itself, with themes that characterize the key competences and meanings discussed by participates ranked in order of power, from the most frequently discussed aspects by the group, to the least (see Appendix Table A1). Since a practice is the integration of materials, meaning, and competences [25], axial coding was then used as a final phase of analysis to connect these interrelated elements [21] under themes that characterize the practice, responsive to the study's research questions. For instance, in conducting the final phase of analysis, the researchers returned to the themes characterizing the practice (competences, meanings), and integrated them under new labels that illuminated how OCR was used by practitioners to reduce production demand, mitigate premature disposal, and foster shared values and identity around social behavior. The new labels were used to organize the Results discussion following. Descriptive statistics were used to summarize results from the screening survey. All phases of analysis included routine peer debriefing sessions between the two authors to ensure the validity of the study's results. The use of practice theory in an OCR context was inherently challenging because this practice is not monolithic, including many different platforms available; not all created equal. Thus, an effort was made during data analysis to identify the overarching routines of OCR and characterize the practice within them, regardless of platform.

\section{RESULTS: THE PRACTICE OF ONLINE CLOTHING RESALE}

All study participants regularly shopped online and had experience on multiple OCR clothing resale platforms, though most were only using one or two platforms on a daily or weekly basis. Approximately $60 \%$ of participants were in their first two years of use, mostly with Poshmark or Facebook Marketplace. Most participants had both selling and buying experience, though over $60 \%$ of them were mostly buying or selling, and only a small number reported using their sale profits to purchase items on the same platform. Further, $75 \%$ of participants reported that less than $40 \%$ of their wardrobe was comprised of second-hand goods. Over $60 \%$ of participants were spending less than $\$ 100$ a month on clothing (including expenditures on OCR platforms). The U.S. Bureau of Economic Analysis reported in 2019 that average annual per capita expenditure on clothing and footwear was approximately $\$ 1100$, though it this varies widely by region and gender. Expenditures are responsive to income, only 7 participants reporting an income exceeding $\$ 70,000$ USD while 11 others reported income under $\$ 20,000$ USD, and several others either did not report or reported income below $\$ 29,000$ USD. It is reasonable to assume these participants reflect a budget to moderate price segment (see Table 1 for full participant summary). There were not relationships between one's income level and whether they were selling or buying or 
both. In regard to the materials utilized to perform the practice, most participants use their smartphone, accessing the OCR platforms via an app, taking images to sell with their phone camera, and occasionally using an outside app like Paypal for payment, all of which are perceived to facilitate busy lifestyles. Very few other resources are required for the practice, except for a printer to generate shipping labels and transport to a post service or meeting locale, where applicable. Following is a description of the themes that characterize the practice of OCR relevant to the study's two research questions, including supporting participant comments (see Appendix Table A1 for illustration of practice).

Table 1. Study participants.

\begin{tabular}{|c|c|c|c|c|c|}
\hline Participant & $\begin{array}{l}\text { Monthly Clothing } \\
\text { Expenditures }\end{array}$ & Platform Experience & $\begin{array}{l}\text { Years of } \\
\text { Practice }\end{array}$ & Buying or Selling & $\begin{array}{l}\text { \% Second-hand in } \\
\text { Wardrobe }\end{array}$ \\
\hline P1 & $\$ 100-200$ & FB Market, Letgo, Tradesy, Depop & $>1$ year & Both; mostly selling & $25 \%$ \\
\hline $\mathbf{P 2}$ & Less than $\$ 100$ & Depop, Letgo, Poshmark & $>1$ year & Buying & $30 \%$ \\
\hline P3 & Less than $\$ 100$ & FB Market, Poshmark, Thredup & $>1$ year & Buying & $30 \%$ \\
\hline $\mathbf{P 4}$ & Less than $\$ 100$ & FB Market, Thredup & $>2$ years & Both: mostly buying & $10-15 \%$ \\
\hline P5 & Less than $\$ 100$ & $\begin{array}{l}\text { FB Market, Letgo, Offerup, Mercari, } \\
\text { Poshmark, Thredup }\end{array}$ & 5 years & Both: mostly selling & $5 \%$ \\
\hline P6 & Less than $\$ 100$ & $\begin{array}{l}\text { FB Market, Letgo, Mercari, Offerup, } \\
\text { Poshmark }\end{array}$ & 1 year & Both & $95 \%$ \\
\hline $\mathbf{P 7}$ & Less than $\$ 100$ & $\begin{array}{l}\text { FB Market, Offerup, Mercari, } \\
\text { Poshmark, Thredup }\end{array}$ & 2 years & Buying & $40 \%$ \\
\hline P8 & Less than $\$ 100$ & FB Market, Poshmark & 1 year & Both & $25 \%$ \\
\hline P9 & Less than $\$ 100$ & FB Market, Poshmark & 4 years & Both & $30 \%$ \\
\hline P10 & $\$ 100-200$ & FB Market, Poshmark & 2 years & Both & $5 \%$ \\
\hline P11 & Less than $\$ 100$ & $\begin{array}{l}\text { Ebay, FB Market, Letgo, Offerup, } \\
\text { Mercari, Tradesey, Thredup, Vinted }\end{array}$ & $>2$ years & Both & $20 \%$ \\
\hline P12 & $\$ 100-200$ & $\begin{array}{l}\text { Ebay, Mercari, Offerup,Poshmark, } \\
\text { 5Miles }\end{array}$ & 4 years & Both; mostly selling & $10 \%$ \\
\hline P13 & Less than $\$ 100$ & FB Market, Poshmark, Mercari & 2 years & Both; mostly selling & $10 \%$ \\
\hline P14 & Less than $\$ 100$ & $\begin{array}{l}\text { Ebay, FB Market, Poshmark, } \\
\text { Mercari }\end{array}$ & 2 years & Both & $75 \%$ \\
\hline P15 & $\$ 100-200$ & $\begin{array}{l}\text { FB Market, Mercari, Poshmark, } \\
\text { Vinted }\end{array}$ & 3 years & Both; mostly selling & $20 \%$ \\
\hline P16 & Less than $\$ 100$ & $\begin{array}{l}\text { Anthropologie FB Resale Group, } \\
\text { Ebay, FB Market, Offerup, } \\
\text { Poshmark }\end{array}$ & 4 years & Both; mostly buying & $65-70 \%$ \\
\hline P17 & Less than $\$ 100$ & FB Market, Poshmark & $>2$ years & Both; mostly selling & $30 \%$ \\
\hline P18 & $\$ 100-200$ & FB Market, Offerup, Poshmark & 3 years & Both & $50 \%$ \\
\hline P19 & Less than $\$ 100$ & FB Market, Offerup, Poshmark & 2 years & Both & $20 \%$ \\
\hline $\mathbf{P 2 0}$ & $\$ 100-200$ & $\begin{array}{l}\text { Ebay, FB Market, Neighborhood } \\
\text { Consignment FB Page, Letgo, } \\
\text { Poshmark }\end{array}$ & 5 years & Both; mostly selling & $10 \%$ \\
\hline
\end{tabular}


Table 1. Cont.

\begin{tabular}{|l|l|l|l|l|l|}
\hline Participant & $\begin{array}{l}\text { Monthly Clothing } \\
\text { Expenditures }\end{array}$ & Platform Experience & $\begin{array}{l}\text { Years of } \\
\text { Practice }\end{array}$ & Buying or Selling & $\begin{array}{l}\text { \% Second-hand in } \\
\text { Wardrobe }\end{array}$ \\
\hline P21 & $\$ 100-200$ & $\begin{array}{l}\text { FB Market, Letgo, Offerup, } \\
\text { Poshmark }\end{array}$ & 1 year & Both; mostly selling & $0 \%$ \\
\hline P22 & Less than $\$ 100$ & FB Market, Poshmark, Mercari & 5 years & Both; mostly selling & $60 \%$ \\
\hline P23 & Less than $\$ 100$ & FB Market, Poshmark & 4 years & Both; mostly selling & $30 \%$ \\
\hline P24 & $\$ 100-200$ & Ebay, Letgo, Poshmark & 5 years & Both; mostly selling & $0 \%$ \\
\hline
\end{tabular}

\section{OCR as a Continuation of the Fashion Marketplace}

With few exceptions, participants understand the basic routines, materials, and required competences of OCR as akin to that of regular retail shopping and resale, a continuation of traditional fashion outlets. For instance, buyers often referred to OCR as "online shopping," motivated by conventional shopping concerns (e.g., convenience, affordability, quality, variety) and employing search and screen competences with online navigational features comparable to regular online retailing. More notable, a clear priority in the practice of OCR is to access and maintain an inventory of goods that reflect the condition, quality, and trendiness of those offered in the conventional fashion marketplace, delivered at comparable speed and a more competitive price. For buyers, OCR is an affordable way to access a wide variety of goods ordinarily outside one's budget. The online platform filters and search functions are skillfully used by buyers to identify goods from desirable brands and barely worn or "like new" clothing (e.g., less than five years old), which most commonly includes clothing for professional dress, jeans, accessories, and some activewear. Participants cited specifically avoiding foundations and other under garments, swimwear, and even shoes, unless they were brand new; considered "weird" or "gross." Brand names signal quality assurance and sizing accuracy. Participants comment:

"I think that there's definitely an advantage because when I buy something, it might look completely brand new but because the person has used it, the price is definitely discounted. Also, I think that even if it has been used or it's a little worn, that doesn't bother me because I'd rather pay the used price or discounted price than buy something that's expensive brand new that it doesn't really matter to me if it's brand new." [P15]

"Usually, you can get a lot better deals. At Poshmark, I'm able to click new with tags. You can like only purchase clothes that still have tags. Just because I like to have clothes that have tags, there's nothing on them and usually I get a better deal on the clothing item." [P13]

"People sell a range of stuff on there, but I think for me personally as a shopper, it's only worth my time to really go through resale stuff if 
I'm going to buy something high-quality that I maybe wouldn't normally be able to afford." [P9]

Similarly, sellers portray OCR as an avenue to recoup value for unused or under-used clothing often at a greater value than if selling through a local resale or consignment shop. Items from the wardrobe that are the newest or older items that are in good shape and are still trendy are considered ideal candidates, according to participants. Sellers cite the golden rule in the selection of goods considered appropriate to sell via OCR: what one would find desirable to buy. Sellers price their items according to rate of wear and original price paid, though many would research similar items that were selling on the app as a guide. The newer the item, the higher the asking price. Sellers also factored in any service or shipping fees to the asking price, anticipating how buyers would evaluate price. Responsively, buyers discussed the competence required to evaluate prices, such as how one weighs the value of shipping fees on other retail websites, though users of Facebook Marketplace preferred the absence of fees and shipping charges in their pursuit of the best price. Further, most OCR platforms like Poshmark offer sellers the option to utilize sales profits to purchase other goods, and a few participants understood this as a method to acquire second-hand goods, achieving some circularity that extends the life of the product. However, most participants routinely cashed out their profits to pay bills or purchase new clothes elsewhere. Sellers identify OCR as an ideal method to dispose of unwanted goods in bulk or one item at a time:

"I definitely thought that the things that I wanted to sell were worth more than what I was getting from like consignment stores in my city like [resale shop], they just kind of undervalue what you give them because they have to make a profit on it, and I was getting tired of that...they're worth what someone is willing to pay for them. I found that selling them online completely changes the value of what something's worth." [P15]

"Mainly it was a way for me to get rid of clothes in my closet while also recycling the funds to get new stuff. It wasn't like I was just donating, giving money away every year by buying these clothes then throwing them away. I was able to sell them for a little bit and then use that money to either buy on those websites or you use it for buying new clothes at a store." [P22]

"I would definitely say it does have to be in good condition. I always make sure-- If I do have a shirt that I do not think would sell, I will donate... I have a lot of clothes that still have a price tag on them and would just sit in my closet for years and I would just never wear it. I just definitely think that it does need to be in good condition and it needs to be good quality. Definitely no stains, no odor, no tears, no rips, anything like that.” [P21] 
Not unlike traditional retailing, both buyers and sellers hold similar expectations for expeditious distribution. Whether meeting in person or shipping an item, participants prioritize the immediacy of acquisition and delivery. For sellers, distribution commonly involves printing a label prepared by the platform, packaging the item to be sold, and delivering the goods to the post office. Some online platforms even mandate a shipping deadline. Likewise, the prepaid shipping labels provided by the platform or the expeditious transaction of an in-person exchange offer comparable convenience to traditional outlets. Most buyers note that shipping time is comparable to other online retailers, if the seller is diligent, while others prefer to meet in person to reduce time-to-acquire, though scheduling challenges may arise:

"I really like [platform]... it's just so easy once someone buys something from you. You just print off the prepaid shipping label, slap it on the box and then drop it off. I think that's definitely the most convenient as opposed to-[platform], it's convenient to meet up with people." [1 6]

"The incentive on [platform] is the sooner that you ship something, usually the better rating you get, and it shows on your profile like what your average shipping time is. Normally, when I buy something, the seller ships it that day or the next day, and it's two-day priority shipping on a lot of websites... That's one of the plus sides of this website." [P15]

"I think the convenience is just that you could walk into the store and probably find something right then and you can take it home right then on your own time. With [platform], I do think it's also convenient because you're getting a good deal for something. But I've noticed personally that sometimes it's hard to find a common time to meet somewhere or even a commonplace." [P18]

More distinctively, participants clearly demarcate OCR from local resale or consignment store experiences. Buyers perceive a better assortment of products than their local second-hand outlets, as one participant commented an advantage to sourcing clothing from "different places like from New York or California; and you know they get different things... so we get better variety.” Some even perceive an advantage to accessing many brands in one place via OCR compared to other online retailers. Likewise, sellers understand OCR as offering greater access to buyers beyond their local market and the general process of merchandising to sell clothing (e.g., photographing, writing, pricing, posting) connotes ease and convenience compared to local resale or consignment store processes.

Though these participants had experience with second-hand trade, in-store and online, they did not articulate the employment of competences to reduce their overall clothing consumption. Also, 
meanings constructed from the practice do not appear to evidence a desire for second-hand clothing itself; at least not clothing that has received much wear. Rather, buying second-hand is agreeable only because goods ordinarily inaccessible can be attained via OCR, and selling second-hand goods is preferable to donating or landfilling clothing often because it provides funds to pay bills or buy new clothes. The relatively low percentage of second-hand clothing in the wardrobes of participants and low occurrences of circularity seem to validate this assertion. Only two participants understood OCR as a "green" prerogative, allowing them to deploy a personal value in their consumption practice, and specifically, to "downsize your wardrobe." While OCR is assuredly mitigating premature disposal of unused or under-used clothing, it does not appear to be a mechanism to reduce new clothing production but rather is simply another outlet to procure fashion at a good price.

\section{In a Crowd of Strangers: Risk and Uncertainty}

"You just have to trust that they are going to send you this item. Honestly, you don't know," a participant said. Both buyers and sellers discussed their understanding of OCR as embodying considerations of risk and uncertainty derived from questionable trustworthiness and unreliability of peers that are distinct from traditional approaches to buying and selling. "Getting scammed" or "screwed over" is an ever-present potential, driven by aspects of both the platform itself as well as other users. For buyers, fraud is an inherent reality to shopping, making the web features, policies, and communication of the platform critical to perceived trustworthiness. If new to a platform, buyers would investigate the terms of sale and shipping prior to purchase. Product information is managed by peers, reliant on the seller's writing aptitude, and is therefore, understood as inherently flawed and requiring scrutiny. Participants discussed the challenges inherent in navigating mistakes in categorization as well as deliberate efforts on the part of sellers to get buyers to view their item; for instance, categorizing an item more broadly. Participants learned through experience how to carefully screen items to ensure the product was being accurately portrayed. This includes carefully reading product descriptions to understand the item's history, looking for "smoke free" or "pet free" homes, inspecting product images carefully for wear or a possible "fake" as well as avoiding sellers who use stock photos, in addition to pointedly investigating the sellers' ratings, "closets," and profile pictures. Generally, buyers noted that, as a rule, they laundered everything, though most sellers discussed cleaning their items before selling. Buyers and sellers perceive refunds as "complicated" due to the fact that funds are held until any dispute is resolved and returns are generally not permitted; as one participant put it, "It's yours to resell." Participants learned to take every precaution to ensure they would receive what they expected: 
"[Platform] has a function-it tries to prevent people from I guess catfishing you. They don't take the money out of your account until you've confirmed that you've received the item and that it's in the condition that they've claimed it was in, which I like because sometimes you're like, 'Oh, I'm a little unsure about this.' It just gives you an extra sense of security about buying it.” [P4]

"Definitely spend more time on [platform] because with the regular online retailer, they are really good about style names and everything, whereas with [another platform] not everybody is, so it might take you a little longer to find what you're looking for." [P9]

"...you're supposed to use real photos and not just the snapshots from whatever brand it is. I rely a lot on that, and on the other listings that they have. Like if it's things that they sell regularly and stuff like that.” [P5]

Participants assume various aspects of making and receiving payments on OCR platforms as necessary and secure, which is most ideally thought to be via the platform itself, which offers direct deposit or a credit balance for its sellers. For users of Facebook Marketplace, Paypal or Venmo were noted as popular methods, though cash in hand was preferable. These participants perceive an inherent risk in meeting their buyer or seller in person for exchange, some describing it as "scary" and even "dangerous", and in this case, the platform does not provide a safety net. Buyers on Facebook Marketplace considered it advantageous to meet in person and inspect before buying, noting the importance of knowing where to meet, preferably in a well-lit public venue. After arranging a meeting online, most drove to meet their buyer or seller within a few miles of their home. A few participants had learned through experience not to meet a person they had not corresponded with or to meet anyone in a private setting, and some participants also discussed declining to purchase the item after they had seen it in person:

"[Platform] is really a lot of having to meet up in person and that you really have to look at the profiles. You're like, 'Okay, maybe they are a good person. Maybe you can trust them,' and with that I think you have to really meet in a public place like a parking lot, or a store or somewhere like that.” [P10]

"I think [platform is] a little harder because it doesn't have any guarantee with it, but usually if I buy something on [platform] I'll meet the seller and like to see the item before I buy it. But I'm a little more cautious about buying things secondhand from [platform]." [P19]

"For [platform], I'll definitely check the item out before I just send them my money and get back in my car... you have to take the risk and hope it's as good as the picture looks or the seller makes it sound. 
I'd say I like that about [platform] more, you can check it out before you fully agree to buying it." [P17]

Some participants noted a small number of incidents in which they did not receive an item or what they received did not meet their expectations, and they were able to receive a refund through the online platform, though it was not easy. Sellers are equally aware of potential scams surrounding those who purchase their items and perceive that in most cases the platform favored the seller in resolving nefarious activity. They learned to take ample pictures, using good lighting and many angles, pictures on and off the body, details of evident wear, and to be transparent in their product descriptions about the item's history. The online platform itself is understood as an important conduit to peace of mind. Buyers perceive additional security in knowing that their payment will not be processed by the platform until they are satisfied with their item:

"I did buy two tops that I had problems with. One of them I actually sent back. I filed a report, which you can do, and sent back the product to the person. It didn't match the description. I felt like the photos were dishonest. There were a lot of stains on the shirt. It's a white top, like a white blouse. There were lots of stains on it that weren't documented in the photos. It hadn't been washed, and it just looked like very worn out for the price point that I paid. I sent that one back." [P5]

"I bought a shirt and it had a giant hole. They hadn't said anything about it, but it was really great working with customer service for [platform]. They were really helpful and understanding. Even though there was a problem, they got worked out and I got my money back and we sent it back and is all taken care of." [P6]

"[Platform], they always go through shipping and as a buyer, I feel safe about that because they provide tracking, if anything gets lost, they absorb that cost. The other one, there's options that buyer or the sellers can choose to ship on their own and I don't do that because then there's no tracking or liability that the app would then absorb. As a buyer and a seller, I always make sure to go through the site for that extra protection." [P22]

Though the rate of objectionable incidents were reportedly low, this perceived atmosphere of distrust and unpredictably is the landscape on which the practice of OCR is performed, where buyers and sellers aim to keep a safe distance. As such, participants report that peer-peer interaction required by OCR platforms is "done pretty anonymously" and is not a social function. Interaction is purely transactional, most commonly understood as a necessity of vetting peers to mitigate fraud. Users routinely make comments on or ask questions about an item, negotiate price, or arrange face-to-face appointments for exchange. A 
small number of participants discussed other interactions such as arranging a trade, a rare instance, or supporting the promotion of each other's items by rating their peers and sharing their online "closets" to boost visibility. One participant who frequently utilized a vintage platform understood her involvement as part of a community with shared values around the preservation of highly coveted goods, though most participants regarded interaction as something to be minimized, as it "feels weird" to interact with strangers:

"I don't necessarily consider it social...it's more of a service, but I have something, or they have something I'm interested in. I'm just asking them more questions about it. It's a little more formal." [P4]

"...in buying things, you gain followers and you make these connections online. Let's say you sell one item, the next time you sell another item, that person who bought from you and it was a good experience they might buy from you again.” [P16]

"Some people really get community and stuff in it, but I'm not really interested in that. I feel if you wanted to seek that out, you could find it. I'm just not interested in that part.” [P5]

While many OCR platforms embody social media features such as commenting, liking, and sharing, these features do not appear to bolster sociality. Without sociality, a sense of community around the practice is absent. The transactional nature of interaction leaves little room for exploration of the practice as a sustainable consumption behavior, influencing one's values or identity toward more sustainable ends.

\section{DISCUSSION}

The aim of this study was to examine the extent to which the practice of online clothing resale (OCR) aligns with fundamental arguments that implicate OCR as a model for sustainable consumption. The first argument is that the utilization of second-hand goods reduces the demand for new products and mitigates premature disposal. The second argument is that self-organization and peer-peer interaction on these platforms facilitates the development of shared values and personal identity that can positively change behavior. Practice theory informed the data analysis approach in this study to illuminate how this practice manifests in everyday life, embodying the various materials, competences, and meanings manifest in the routines of the practice. How practitioners (i.e., consumers) utilize OCR platforms, derive and apply knowledge or skills in use, and perceive this activity are used in the following to discuss the researchers' evaluation of the ways in which this practice may functionally deliver sustainable consumption gains (or not). 


\section{Does Online Clothing Resale Reduce Demand for New Production and Mitigate Premature Disposal?}

The particulars of OCR practice elucidated in this study raises doubts about the positioning of these platforms as a truly unique or alternative type of consumption [3,14], which arguably will limit its capacity to yield sustainable consumption. Clear in the examination of buyers' meanings derived from the practice is the perception of OCR as a continuation of traditional retail, especially in regard to the portrayal of meanings such as affordability, convenience, and quality, which are not uncommon aims of shopping generally. Within the key routines of the practice, search and screen techniques of the platforms, the transactional nature of interactions, and payment and distribution habits were all akin to what a buyer would expect from traditional online retailers. There is not much of a learning curve required to navigate OCR. Arguably, how platforms are perceived influences how consumers use them, and in this case, the practice of OCR finds little distinction from conventional models offering cheap fashion in quantity, which works against sustainable consumption $[3,14,15]$.

Women who participated in this study were not necessarily second-hand consumers, as evidenced by the relatively low percentage of their wardrobe they reported to be second-hand. Rather, they prioritized the competences of search and screen approaches to find affordable, branded, and high-quality items, and preferably, clothing that was barely worn or new with tags. There is little indication of an effort to substitute the acquisition of new products with second-hand goods [15] or to even retain these clothing longer as to poise it for emotional attachment [3]. Purchasing second-hand is a worthwhile sacrifice to attain goods ordinarily inaccessible. Iran and Schrader [15] question the sustainability gains of collaborative clothing consumption practice that embodies a significant cost savings as it could encourage consumers to purchase more goods overall due to the cost savings which does little to curb overall garment production and could increase disposal. These findings provide context to explain why environmental sustainability generally does not predict collaborative consumption intention [8] and could even encouraged more indulgent consumption via an OCR platform [19].

Moreover, sellers frequently dispose of clothing in ideal condition that has been unused or underused, which seems to suggest a pattern of unnecessary accumulation. There is also a relatively low occurrence of sellers using the platforms to acquire more second-hand clothing with their OCR profits, evidencing a low rate of circularity that could potentially extend the product lifetime of clothing [11]. The practice or desire to use these platforms to curb clothing acquisition or even a preference for second-hand goods over new was wholly absent from the portrayal of the practice by participants. To be sure, recirculating clothing that might ordinarily find its way to landfill, even if it was never or rarely worn, is an environmental win [2,5,11]. However, this could be 
more reasonably categorized as waste diversion rather than confidently supporting the ideals of "circularity" that meaningfully reduce new clothing acquisition or accumulation, though a few sellers in the study discussed the practice as a method to simplify and reduce household clutter.

\section{Does Online Clothing Resale Foster Sociality that Facilitates Shared Values and Identity around Sustainable Consumption Behavior?}

Though the literature has long explored the environmental benefits of consumption models such as OCR, and many have touched on the social impacts of such business models [38], the investigation of peer-to-peer sociality and its influence on consumption behavior change is a relatively new research focus [15]. Previous studies support the contention that the more sociality, or a sense of community, can be fostered within consumption activities the greater the chance that shared values around an alternative practice may develop, shaping one's identity [12,13,15,38], even inspiring a political orientation to one's consumption choices [34-36]. In their recent typology of collaborative fashion consumption models, Iran and Schrader [15] clarify that most peer-to-peer interaction in the context of clothes "sharing" occurs in offline events (e.g., parties), often promoted online, such as via social media. At these events, where being social is more of the focus, users can bond in their mutual interest of sustainable consumption practices. This is, of course, speculation. The current study sought to illuminate, at least partially, the nature of sociality in the experience of online interaction and how this integrates in the practice of OCR. Social media features implicated in the routines of OCR (e.g., liking, commenting, sharing) seem to broach social interaction, providing the appearance of a community that cares about waste reduction or recycling [15]. Yet, according to the portrayal of OCR practice by the research participants in the current study, this is a wholesale misconception. These participants understand the practice as one that requires competence to mitigate risk and uncertainty rather than an exchange within a like-minded community. Interestingly, earlier research has highlighted potential issues of trustworthiness with collaborative clothing consumption partly driven by how innovative this form of consumption practice is perceived [39]. Even earlier researchers urged collaborative consumption business to clearly articulate their policies and explain how they effectively deliver outcomes [40,41]. Yet, for participants in this study, the business practices of the platform were, in fact, a chief mechanism that encouraged trust.

Central in the experience of OCR practice is an alertness to the potential ill motives of strangers (i.e., peers rather than the facilitating business itself) that seem to work against a sense of community. Interaction is subsequently transactional, even considered undesirable by many participants, though one participant indicated that her experience on Depop was far more communal in that the preservation of 
vintage goods was a value she had in common with other users. Perhaps, luxury or vintage platforms, which were not the focus in this study, offer more opportunities for shaping a more sustainability-oriented identity by more narrowly segmenting consumers into groups who really care about and desire such interaction [12,15]. Jaeger-Erben et al. [12] note that self-organization on these platforms could raise the level of consumer engagement, making a more alternative consumption model more viable. Arguably, aside from the merchandising decisions of sellers, negotiation between buyers and sellers, and the arrangement of in-person product exchanges, most aspects of OCR practice are facilitated by the business, and this is actually perceived by the users as an advantageous element to OCR, reducing perceived risk and uncertainty. This aspect of the study's findings most highlight the need for more research about the capacity of OCR to buoy the social capital requisite to meaningfully shift consumer behavior [12,37]. At present, this does not appear to be a meaningful experience in the context of OCR.

\section{CONCLUSIONS}

It must be concluded that current OCR practice only loosely supports the fundamental arguments being used to associate collaborative consumption with sustainable consumption. A culture that values second-hand exchange is evidently missing from the practice among young women who use OCR platforms. This study also raises valid questions about the degree to which OCR truly increases clothing product longevity by reducing a demand for new goods. Theoretically, this research has provided a detailed illustration of OCR as a practice manifest in the real lives of budget-conscious young women, extending a broad base of conceptual speculation and behavior intention models developed by previous researchers. This study has clarified misconceptions about OCR as a community of waste-conscious consumers, and more aptly situated it as an extension of the fashion marketplace; not an alternative model of consumption. Practitioners do not see OCR as alternative nor do they necessarily perform the practice of OCR in a manner unlike that of conventional fashion retailing. This project has also delineated the origin of perceived risk and uncertainty as driven by a distrust in one's peers, not the platform itself, which fundamentally prohibits the development of community. A related managerial implication is that platforms that wish to position themselves to reorient consumption behavior must do so more pointedly, possibly deploying the features of social media to more meaningfully drive peer-to-peer interaction and organization; for example, using these features to help users display their trustworthiness, beyond the standard review system, or making it easier to have an online chat about a product in question. On the other hand, there is also the possibility that increasing the capacity for sociality in the design of OCR platforms such as Poshmark or Facebook Marketplace may be patently undesirable, given 
the express budget-conscious intent of users. There is a critical need for more research concerning the sociality of these platforms and its potential to boost social capital sufficient to advance behavior to more sustainable ends.

\section{LIMITATIONS AND FUTURE RESEARCH}

Online clothing resale is a highly diverse sector of the collaborative consumption marketplace from both business model and consumer standpoints. The purpose of this study was to examine a window into the practice generally, though much more depth could be obtained by narrowing the research query. For instance, participants in this study had utilized platforms with widely varying levels of business involvement, from platforms such as ThredUp, where the consumer has little to do with sales transactions, to Poshmark where sales are only facilitated by the business, to Facebook Marketplace where the consumer is entirely responsible for all activities supporting the transaction, including in-person distribution. In-depth research about varying models could be beneficial, particularly regarding concepts like sociality, as some platforms operate in a way that limits interaction. Most participants spent less than $\$ 100$ per month on clothing and were utilizing platforms that represented a budget to moderate price segment, excluding luxury, indicating they were budget-conscious. Future research about the luxury segments of OCR, which are increasing in the marketplace, would include the study of older participants who may desire different levels of sociality. Over half of the participants were either buying or selling, and not necessarily participating in a circular type of second-hand consumption. A much richer understanding of these roles could be gleaned in future research by focusing on one or the other. Though most clothing bought and sold by study participants seemed to be relatively new, this study did not specifically investigate the lifespan of the clothing exchanged, and this type of examination could further illuminate the viability of OCR as a method of sustainable consumption, especially in comparison to other models of collaborative consumption such as renting.

\section{DATA AVAILABILITY}

The dataset of the study is available from the authors upon reasonable request, though an institutional approval process is necessary to transfer data outside the U.S.

\section{AUTHOR CONTRIBUTIONS}

Both authors collaboratively designed the study, and the first author conducted the interviews. The first author initially categorized and identified emergent themes, which were routinely reviewed by the second author. The authors worked together to identify and validate the study's final themes as well as outline and draft the final paper. 


\section{CONFLICTS OF INTEREST}

The authors declare that there is no conflict of interest.

\section{FUNDING}

This project was supported by a fellowship received by the first author from the Riata Center for Entrepreneurship at Oklahoma State University.

\section{APPENDIX}

Table A1. Analysis of OCR practice.

\begin{tabular}{|c|c|c|}
\hline Routines & Competences (knowledge + skills) & Meanings \\
\hline $\begin{array}{l}\text { Search and Screen } \\
\text { For buyers } \\
\text { - Search } \\
\text { Materials } \\
\text { - Smart phone; retail app }\end{array}$ & 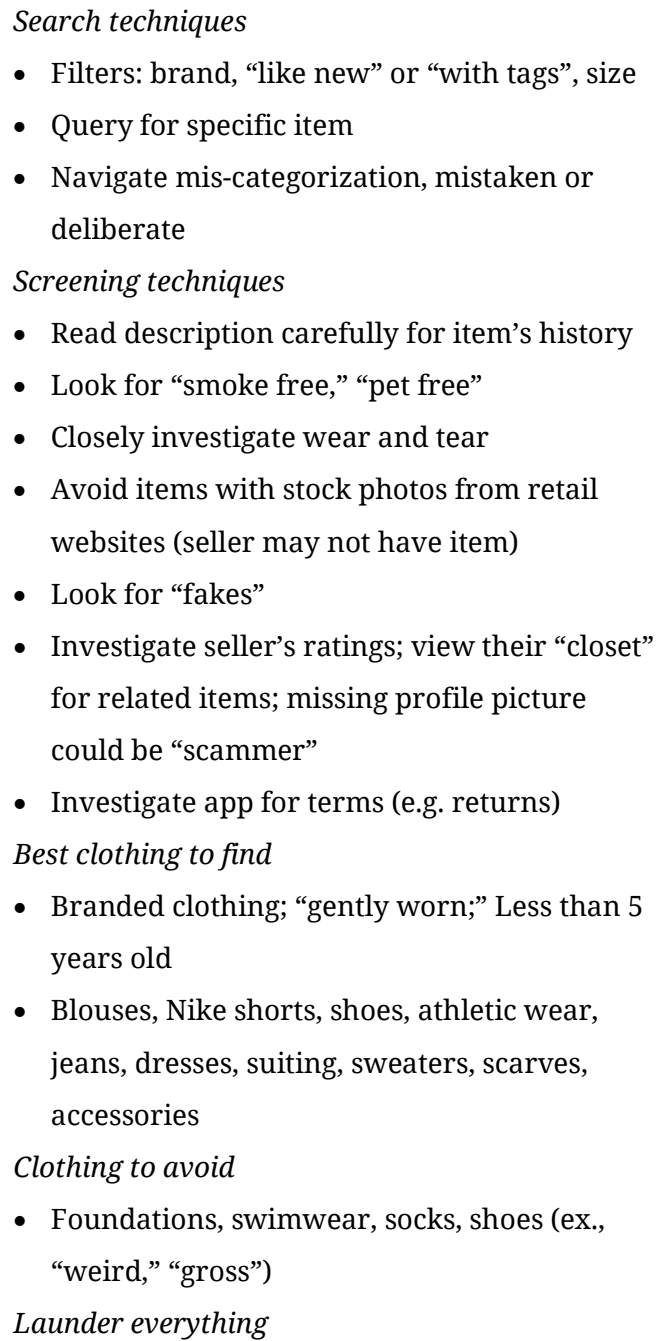 & $\begin{array}{l}\text { Similar to shopping generally, and traditional } \\
\text { online retail and resale models; extension of } \\
\text { fashion marketplace } \\
\text { Affordable } \\
\text { - Access products ordinarily outside budget } \\
\text { Convenience } \\
\text { - Search filters = efficiency } \\
\text { - No "hunt” compared to second-hand stores } \\
\text { Access variety } \\
\text { - Many brands in one place (compared to } \\
\text { regular online retail) } \\
\text { - Wider second-hand assortment not available } \\
\text { locally } \\
\text { Quality } \\
\text { - Rate of wear is at premium; second-hand } \\
\text { goods are most agreeable when "like new" } \\
\text { - Brand names ensure quality and correct } \\
\text { sizing } \\
\text { Trustworthiness-reliability } \\
\text { - Fraud is inherent; users are inconsistent } \\
\text { - Clear app policies foster trust (e.g., returns, } \\
\text { - payment, fees) } \\
\text { Aligns with "green" prerogative* }\end{array}$ \\
\hline
\end{tabular}


Table A1. Cont.

\begin{tabular}{|c|c|c|}
\hline Rou & dge + skills) & ngs \\
\hline $\begin{array}{l}\text { Merchandising } \\
\text { For sellers } \\
\text { - Selecting } \\
\text { - Photographing } \\
\text { - Writing } \\
\text { - Pricing } \\
\text { - Posting } \\
\text { - Re-listing } \\
\text { Materials } \\
\text { - Smart phone; } \\
\text { retail app; } \\
\text { phone camera }\end{array}$ & $\begin{array}{l}\text { Knowing what is appropriate to sell on app } \\
\text { - "Treat others how you want to be } \\
\text { treated" } \\
\text { - Can sell older items, if still on trend } \\
\text { "Products are worth what people are } \\
\text { willing to pay for them;" set price based } \\
\text { on: rate of wear, original price, prices } \\
\text { paid for similar items; less wear yields } \\
\text { higher price; factor in shipping/service } \\
\text { fees } \\
\text { Provide rich description, including use } \\
\text { details; "that the more detailing they put } \\
\text { and more pictures, the easier it sells" } \\
\text { Take ample pictures; many angles, good } \\
\text { lighting, clean background, garments on } \\
\text { the body; photograph interior labels, } \\
\text { worn places, special details; do not add } \\
\text { filters; avoid using stock photos from } \\
\text { websites } \\
\text { Re-list to bump listing to top in app; } \\
\text { periodically drop price } \\
\text { Consider of related fees on price paid } \\
\text { - Service fees }\end{array}$ & 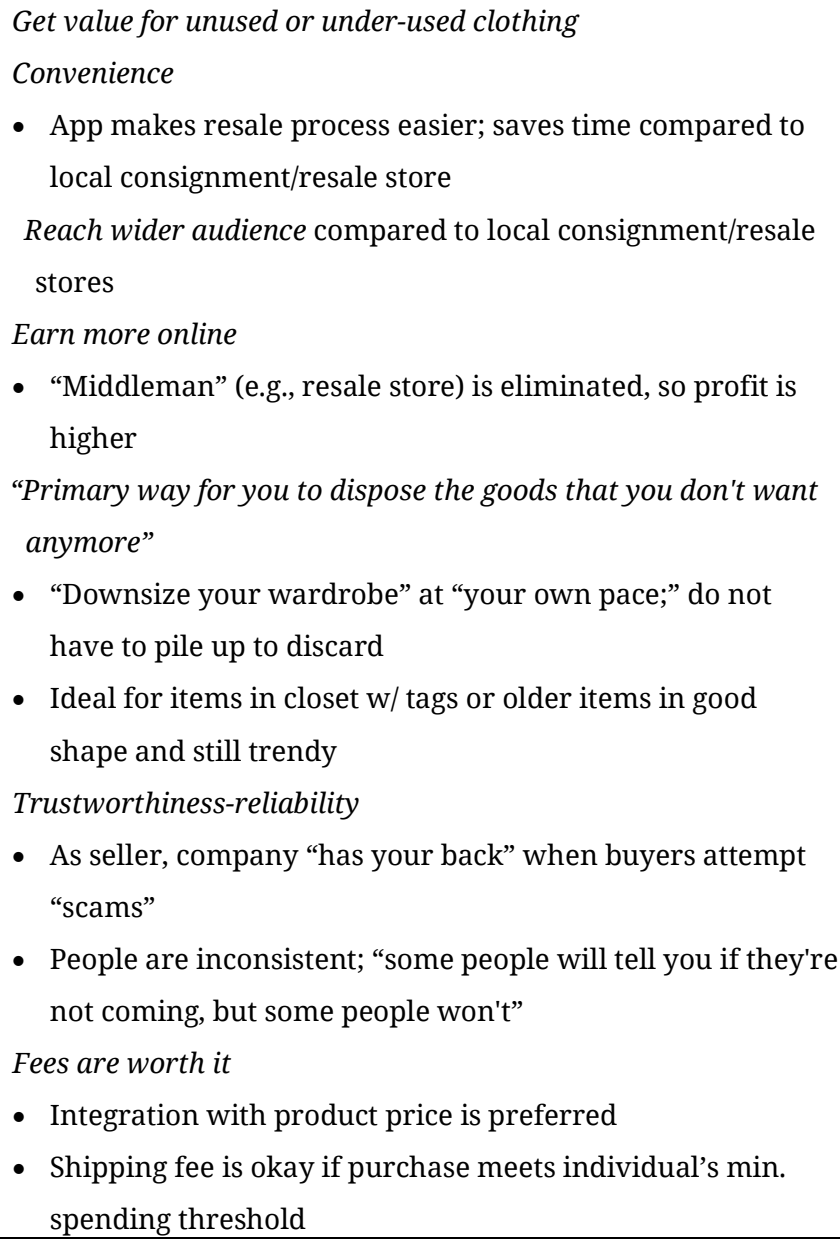 \\
\hline $\begin{array}{l}\text { Interacting } \\
\text { - } \text { Commenting } \\
\text { Messaging } \\
\text { - Responding } \\
\text { - Sharing } \\
\text { - Vetting peers } \\
\text { Materials } \\
\text { - Smart phone; } \\
\text { retail app } \\
\end{array}$ & $\begin{array}{l}\text { - Negotiate price } \\
\text { - Ask questions about the product; ask for } \\
\text { more pictures } \\
\text { - Arrange appointment for exchange or } \\
\text { trade } \\
\text { - Share others' "closets" increases } \\
\text { followership } \\
\text { - Ask others to rate you } \\
\text { - Send "thank you" note in the package }\end{array}$ & $\begin{array}{l}\text { - Interaction is "just transactional," not social; the app is a } \\
\text { service; no "emotional connection;" "not something that I } \\
\text { usually find identity in;" "done pretty anonymously" } \\
\text { - Direct messaging "feels weird" } \\
\text { - } \text { Mitigate fraud; method to vet peers }\end{array}$ \\
\hline $\begin{array}{l}\text { Paying } \\
\text { - Making } \\
\text { - Receiving } \\
\text { Materials } \\
\text { Smart phone; retail } \\
\text { app; Paypal, } \\
\text { Venmo }\end{array}$ & $\begin{array}{l}\text { Use reputable payment method } \\
\text { - Paypal, Venmo, credit card, direct } \\
\text { deposit from app, cash, virtual currency } \\
\text { Returns not optional }\end{array}$ & $\begin{array}{l}\text { Security } \\
\text { - Payment is delayed until buyer is satisfied } \\
\text { - Platform operations = peace of mind } \\
\text { - In-person meeting is a risk; online platform is not involved } \\
\text { Returns/refunds are "complicated" } \\
\text { - Frustration by seller if funds are held up } \\
\text { Low Circularity } \\
\text { - Credit from previous sales is used to pay bills or new } \\
\text { clothing elsewhere; infrequently used to acquire } \\
\text { second-hand goods to extend product lifetime }\end{array}$ \\
\hline
\end{tabular}


Table A1. Cont.

\begin{tabular}{|l|l|l|}
\hline Routines & Competences (knowledge + skills) & Meanings \\
\hline $\begin{array}{l}\text { Distributing } \\
\text { - Printing label }\end{array}$ & $\begin{array}{l}\text { Seller should prepare box \& ship expeditiously } \\
\text { - Packaging item }\end{array}$ & $\begin{array}{l}\text { Convenience } \\
\text { - Prepaid shipping labels are easy; must print } \\
\text { - Deliver to post office } \\
\text { - Or Meeting }\end{array}$ \\
$\begin{array}{l}\text { Materials } \\
\text { Smart phone; retail app; } \\
\text { printer; transport to post } \\
\text { office; meeting locale }\end{array}$ & & $\begin{array}{l}\text { - Meeting locally saves time to acquire item } \\
\text { if seller mails expeditiously }\end{array}$ \\
& & \\
\hline
\end{tabular}

\section{REFERENCES}

1. Botsman R, Rogers R. What's mine is yours: The rise of collaborative consumption. New York (NY, US): Harper Collins; 2010.

2. Leismann K, Schmitt M, Rohn H, Baedeker C. Collaborative consumption: Towards a resource-saving consumption culture. Resources. 2013;2:184-203.

3. Joyner Armstrong CM, Park H. Sustainability and collaborative clothing consumption: putting the digital 'sharing' economy under the microscope. Int J Fash Des Technol Educ. 2017;10(3):276-86.

4. Park H, Joyner Armstrong CM. Collaborative apparel consumption in the digital sharing economy: An agenda for academic inquiry. Int J Consum Stud. 2017;41:465-74.

5. Reim W, Parida V, Örtqvist D. Product-service systems (PSS) business models and tactics—a systematic literature review. J Clean Prod. 2015;97:61-75.

6. Ellen MacArthur Foundation. A new textiles economy: redesigning fashion's future. Cowes (UK): Ellen MacArthur Foundation; 2017. Available from: http://www.ellenmacarthurfoundation.org/publications. Accessed $2019 \mathrm{Jul} 1$.

7. Lehmann M, Tärneberg S, Tochtermann T, Chalmer C, Eder-Hansen J, Seara J, Deichmann S. Pulse of the fashion industry. Copenhagen (Denmark): Global Fashion Agenda; Boston (MA, USA): The Boston Consulting Group; 2018. Available from: https://globalfashionagenda.com/wp-content/uploads/2017/ 05/Pulse-of-the-Fashion-Industry 2017.pdf. Accessed 2019 Jul 1.

8. Hamari J, Sjöklint M, Ukkonen A. The sharing economy: Why people participate in collaborative consumption. J Assoc Inf Sci Technol. 2015;67(9):2047-59.

9. Barnes SJ, Mattsson J. Understanding current and future issues in collaborative consumption: A four-stage Delphi study. Technol Forecast Soc Change. 2016;104:200-11.

10. Tsui KK. Economic explanation: From sharecropping to the sharing economy. Man Econ. 2016;3(1):77-96.

11. Niinimäki K. Sustainable Fashion in a Circular Economy. In: Niimiaki K, editor. Sustainable Fashion in the Circular Economy. Espoo (Finland): Aalto ARTS Books; 2018. p. 12-41. 
12. Jaeger-Erben M, Rückert-John J, Schafer M. Sustainable consumption through social innovation: A typology of innovations for sustainable consumption practices. J Clean Prod. 2015;108:784-98.

13. Mont O. Institutionalisation of sustainable consumption patterns based on shared use. Ecol Econ. 2004;50:135-53.

14. Baumeister CK. Access versus ownership: Consumers' reactions to an alternative consumption mode [dissertation]. Munich (Germany): Technische Universität München; 2014.

15. Iran S, Schrader U. Collaborative fashion consumption and its environmental effects. J Fashion Market Manag. 2017:21(4):468-82.

16. Becker-Leifhold C, Iran S. Collaborative fashion consumption: Drivers, barriers and future pathways. J Fashion Market Manag. 2018;22(2):189-208.

17. Johnson KKP, Mun JM, Chae Y. Antecedents to internet use to collaboratively consume clothing. J Fashion Market Manag. 2016;20(4):370-82.

18. Lang C, Joyner Armstrong CM. Collaborative consumption: The influence of fashion leadership, need for uniqueness, and materialism on female consumers' adoption of clothing renting and swapping. Sustain Prod Consum. 2018;13:37-47.

19. Parguel B, Lunardo R, Benoit-Moreau F. Sustainability of the sharing economy in question: When second-hand peer-to-peer platforms stimulate indulgent consumption. Technol Forecast Soc Chang. 2017;125:48-57.

20. Hargreaves T. Practice-ing behavior change: Applying social practice theory to pro-environmental behaviour change. J Consum Cult. 2011:11(1):79-99.

21. Røpke I. Theories of practice-New inspiration for ecological economic studies on consumption. Ecol Econ. 2009;68:2490-7.

22. Reckwitz A. Toward a theory of social practices a development in culturalist theorizing. Eur J Soc Theory. 2002;5(2):243-63.

23. Warde A. Consumption and theories of practice. J Consum Cult. 2005;5(2):131-53.

24. Weinswig D. Deep dive: Fashion re-commerce evolution. Hong Kong (China): The Fung $\quad$ Group; $2017 . \quad$ Available from: http://www.deborahweinswig.com/wp-content/uploads/2017/06/Fashion-ReCommerce-Update\%E2\%80\%9412-Catalysts-for-Clothing-Resale-Growth-June -29-2017.pdf. Accessed 2019 Jul 1.

25. Fuentes C. Managing green complexities: consumers' strategies and techniques for greener shopping. Int J Consum Stud. 2014;38:485-92.

26. Mylan J. Understanding the diffusion of sustainable product-service systems: Insights from the sociology of consumption and practice theory. J Clean Prod. 2015;97:13-20.

27. Pereral C, Auger P, Klein J. Green consumption practices among young environmentalists: A practice theory perspective. J Bus Ethics. 2018;152:843-64.

28. Cooper T. Longer lasting products: alternatives to the throwaway society. Farnham (UK): Gower; 2010.

29. Cooper T, Hughes M, Claxton S. From rag trade to retail: garment failure and the potential for sustainable fashion. In: Cooper T, Braithwaite N, Moreno M, 
Salvia G, editors. Proceedings from Product Lifetimes and Environment (PLATE) Conference. Nottingham (UK): Nottingham Trent University, CADBE; 2015. p. 73-80.

30. Gil A, Lopes AM, Kaye-Smith H. Practicing sustainability: Illuminating 'use' in wearing clothes. Cultural Stud. 2016;22(1):32-58.

31. Laitala K, Boks C. Sustainable clothing design: use matters. J Des Res. 2012:10(1/2):121-39.

32. Farrant L, Olsen SI, Wangel A. Environmental benefits from reusing clothes. Int J Life Cycle Assess. 2010;15(7):726-36.

33. Woolridge AC, Ward GD, Phillips PS, Collins M, Gandy S. Life cycle assessment for reuse/recycling of donated waste textiles compared to use of virgin material an UK energy saving perspective. Resour Conserv Recy. 2006;46(1):94-103.

34. Albinsson PA, Perera BY. Alternative marketplaces in the 21st century: Building community through sharing events. J Consum Behav. 2012;11:303-15.

35. Binninger A-S, Ourahmoune N, Robert I. Collaborative consumption and sustainability: A discursive analysis of consumer representations and collaborative website narratives. J Appl Bus Res. 2015;31:969-86.

36. Philip HE, Ozanne LK, Ballantine PW. Examining temporary disposition and acquisition in peer-to-peer renting. J Market Manag. 2015;31(11-12):1310-32.

37. Chou C-J, Chen C-W, Conley C. An approach to assessing sustainable product-service systems. J Clean Prod. 2015;86:277-84.

38. Thorisdottir T, Johannsdottir L. Sustainability within fashion business models: A systematic literature review. Sustainability. 2019;11:2233.

39. Armstrong CM, Niinimäki K, Kujala S, Karell E, Lang C. Sustainable product service systems for clothing: Exploring consumer perceptions of consumption alternatives in Finland. J Clean Prod. 2015;97:30-9.

40. Rexfelt O, Ornäs VH. Consumer acceptance of product-service systems. J Manuf Tech Manag. 2009;20(5):674-99.

41. Schrader U. Consumer acceptance of eco-efficient services. Green Manag Int. 1999;25:105-21.

42. Strauss A, Corbin J. Basics of qualitative research: Grounded theory procedures and techniques. London (UK): Sage; 1990.

How to cite this article:

Joyner Armstrong CM, Park H. Online Clothing Resale: A Practice Theory Approach to Evaluate Sustainable Consumption Gains. J Sustain Res. 2020;2(2):e200017. https://doi.org/10.20900/jsr20200017 